\title{
RADIOGRAPHIC INVESTIGATION OF DENTAL ANOMALIES IN LIBYAN ORTHODONTIC PATIENTS.
}

Iman Abdelgader ${ }^{1}$, Tyisir Gnaiber ${ }^{1}$, Kadija Emnina ${ }^{2}$ and Sulieman Orofi ${ }^{1}$

${ }^{1}$ Department of Orthodontics, Faculty of Dentistry, University of Benghazi, Libya

2Benghazi Dental center, Benghazi-Libya.

\section{ARTICLE INFORMATION:}

\section{Article History:}

Received: 22 May, 2014

Accepted in revised form: 17 August,

2014

Published: 1 August, 2015

Corresponding author:

Iman Abdelgader

E-mail: iman.ag@dr.com

\section{Keyword:}

dental anomalies ,Prevalence, Malocclusion, Libyans

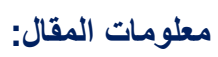

\begin{tabular}{|c|}
\hline 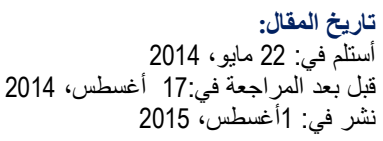 \\
\hline المأن عبدالقادورل: \\
\hline
\end{tabular}

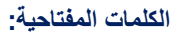
تشوهات الاسنان ، سوء الطباق، الليبين

\section{ABSTRACT:}

Aim: The purpose of this study was to evaluate the prevalence of dental anomalies in different Libyan orthodontic malocclusions.

Materials and Methods: Pretreatment orthodontic records of 252 Subjects (57 Males and 195 Females) were classified as Class I (159), Class II Division I (66), Class II Division II (8) and Class III (19). The incidence rates of specific dental anomalies were investigated and analyzed to study the differences of rates of each anomaly according to sex and malocclusion using descriptive analysis

Result: It was found that (53.5\%) of the patients had at least one dental anomaly in this study. ectopic eruption was the most prevalent dental anomaly (34.9\%) followed by thin pipette-shaped roots and short blunt root $(30.1 \%, 24.2 \%)$ respectively.

Conclusions: Male subjects showed more ectopic eruption and short blunt root then female, Class I malocclusion had the most prevalent dental anomalies compared to the other malocclusion groups.

الملخص العربي

التحقيق الشعاعي لتشوهات الأسنان لاى مرضى تثويم الأسنان الليبين

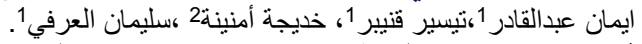

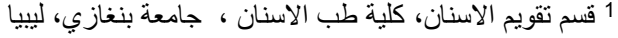

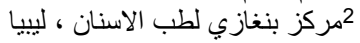

الهرف: كان الهدف من هذه الدراسة هو تقييم مدى انتشار تشوهات الأسنان في حالات سوءُ iman.ag@dr.com الإطُباق المختلفة لدى عيادات تقويم الأسنان الليبية.

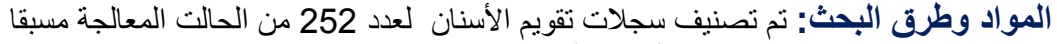

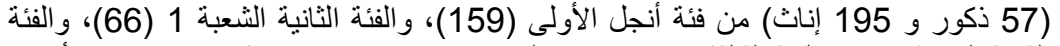

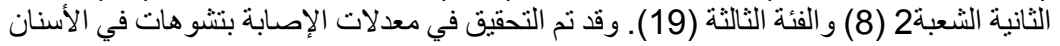

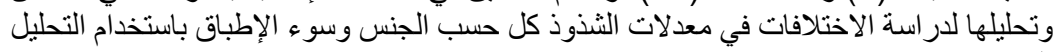

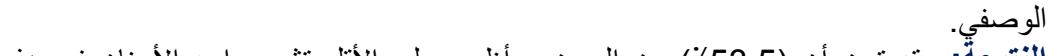
النتيجة: وقد تبين أن (53.5٪) من المرضى أظهر على الأقل تشوه واحد الأسنان في هذه

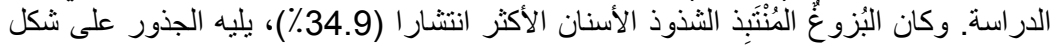

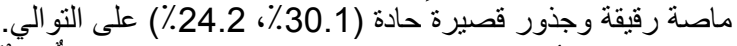

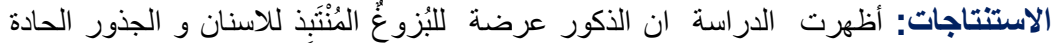

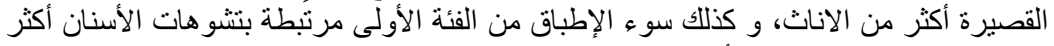
مقارنة بفئات سوء الإطباق الأخرى.

Copyright $\odot$ 2013. LDJ. This is an open access article distributed under the Creative Commons Attribution 3.0 License, which permits unrestricted use, distribution, and reproduction in any medium, provided the original work is properly cited. 
INTRODUCTION:

Developmental anomalies of dentition result from disturbances during the morphological differentiation of tooth germ $^{1}$. These disturbances may result from genetic and/or environmental factors. The outcomes of those events result in abnormality in tooth number, shape and position which may interfere with the normal development of occlusion ${ }^{2}$. Many previous researches investigated the incidence of various dental anomalies in different populations, however their results were conflicting which could be attributed to racial differences, variable sampling techniques and different diagnostic criteria $^{3.4}$. The aim of this study was to estimate the incidence and distribution of certain dental anomalies in the Libyan orthodontic Patients.

\section{MATERIALS AND METHODS:}

The study was undertaken relaying on pretreatment records (Orthopantomograph and initial study models) of (252) Libyan orthodontic patients (195 Female, 57 Male) .The mean age of patients was 19.5 year. All subjects were in permanent dentition. The selection of the subjects was based on the following criteria:1)No significant medical history,2)No history of extraction of any permanent tooth before the study,3)All pretreatment X-ray records were taken by the same $\mathrm{x}$-ray machine with the same standardized method,4)No history of endodontic treatment or trauma to any tooth before the study. The subjects were classified into 4 groups of different malocclusion type according to Steiner analysis (5) as the following: Class I (ANB angle 0 to 4 degree) $(\mathrm{N}=159,63.1 \%)$, Class II Division I (ANB angle $>4$ degree $)(\mathrm{N}=66,26.2 \%)$, Class II Division II (ANB angle $>4$ degree $)(\mathrm{N}=8,3.2 \%)$ Class III (ANB angle $<0$ degree) $(\mathrm{N}=19,7.5 \%)$. The following dental anomalies were investigated: Agenesis: a congenital absence of a permanent tooth or germ $^{6}$. Invagination: a developmental malformation resulting from invagination of the crown or root surface before calcification. Short or blunt roots: Roots as long as or shorter than the crowns in the incisors and visually evaluated as short, blunt roots bilaterally in the posterior teeth were recorded as short or blunt roots $^{7}$. Thin, pipette-shaped roots: The apical part of the root is thin with a biconcave form $^{8}$. Ectopic eruption: Eruption of a tooth in an abnormal position ${ }^{9}$. Impaction: a tooth that is not expected to erupt completely into its normal functional position based on clinical and radiographic assessment ${ }^{10}$.Peg-shaped lateral incisors: a peg lateral is defined as 'an undersized, taper maxillary lateral incisor ${ }^{11}$. Supernumerary: teeth that appear in addition to the regular number of teeth ${ }^{6}$. Dilacerations: a deviation or bend in the linear relationship between tooth crown and root, an angulation or sharp curve of $90^{\circ}$ or more in the root or crown of a developed tooth ${ }^{12}$. In order to eliminate interexaminer error. All records were examined by the same clinician who has 5 years of professional experience.

\section{Statistical analysis:}

Repeatability was tested on 30 randomly selected subjects examined at least 4 weeks after the initial examination. Kappa coefficients were calculated to determine the reliability of determining each dental anomaly in the 2 evaluation periods. Numbers of patients and rates of dental anomalies were calculated for the overall study sample, and by sex and malocclusion type. Chi-square was conducted to determine the statistical significance of dental anomalies by sex and malocclusion type. The data were entered into an Excel spread sheet (Microsoft Office 2007) and analyzed with the Statistical Package for Social Sciences version 21 SPSS, Chicago, Illinois.

\section{RESULTS:}

A total of 117 subjects had no anomaly, whereas 62 had one anomaly and 73 showed more than one dental anomaly. (Table 1).

Table (1) Frequencies of number of dental anomalies exhibited in orthodontic patients

\begin{tabular}{|l|l|l|l|l|l|l|}
\hline Variables & \multicolumn{2}{|c|}{ Females(19) } & \multicolumn{2}{|l|}{ Males(57) } & \multicolumn{2}{|c|}{ Total (76) } \\
& $\mathrm{N}$ & \multicolumn{1}{l|}{$\%$} & \multicolumn{2}{|l|}{$\mathrm{N}$} & \multicolumn{2}{c|}{$\%$} \\
\hline $\begin{array}{l}\text { No } \\
\text { anomaly }\end{array}$ & 91 & 36.1 & 26 & 10.3 & 117 & 46.4 \\
\hline $\begin{array}{l}\text { One } \\
\text { anomaly }\end{array}$ & 51 & 20.2 & 11 & 4.3 & 62 & 24.6 \\
\hline $\begin{array}{l}\text { >one } \\
\text { anomaly }\end{array}$ & 53 & 21 & 20 & 7.9 & 73 & 28.9 \\
\hline
\end{tabular}

Ectopic eruption was the most prevalent dental anomaly in this study which constituted $34.9 \%$ of the patients. Maxillary lateral incisors and canines were most often affected. Male were more likely to show ectopic eruption than female $(\mathrm{p}<0.01)$.The second most common anomaly was thin pipette-shaped roots. It accounted for $30.1 \%$ of the patients. The frequency of short blunt roots 
was $24.2 \%$. It was further found that male were more likely to show short blunt roots than female ( $p$ value $<0.05$ ). Lower central incisors and lower first premolars were most frequently found to show short blunt roots. Agenesis, impaction and peg-shaped laterals were considerably less frequently encountered anomalies they were found in $9.9 \%, 7.5 \%$ and $3.1 \%$ respectively.
Supernumerary teeth were detected in only $1.19 \%$ of the patients. Males more likely to show supernumerary teeth than females ( $p$ value $<0.01$ ). Supplemental lower lateral incisor were found to be the most common supernumerary tooth. Dilaceration was found in only one patient. (Table 2).

Table (2) distribution and prevalence of dental anomalies in study group and chi square tests of differences between sexes.

\begin{tabular}{|c|c|c|c|c|c|c|c|c|c|}
\hline \multirow[t]{2}{*}{ Anomalies } & \multicolumn{2}{|c|}{ Female (195) } & \multicolumn{2}{|c|}{ Male (57) } & \multicolumn{2}{|c|}{ Total (252) } & \multirow{2}{*}{$\begin{array}{l}\text { Teeth most } \\
\text { affected }\end{array}$} & \multirow{2}{*}{$\begin{array}{l}\text { Chi } \\
\text { sq. }\end{array}$} & \multirow[t]{2}{*}{$P v$} \\
\hline & $\mathrm{N}$ & $\%$ & $\mathrm{~N}$ & $\%$ & $\mathrm{~N}$ & $\%$ & & & \\
\hline Invagination & 0 & 0 & 0 & 0 & 0 & 0 & ---- & --- & --- \\
\hline Short blunt roots & 40 & 15.8 & 21 & 8.3 & 61 & 24.2 & $34,31,41,44$ & 6.4 & 0.01 \\
\hline Thin, pippet-shaped roots & 62 & 24.6 & 14 & 5.5 & 76 & 30.1 & $35,34,36,46$ & 1.09 & 0.29 \\
\hline Ectopic eruption & 59 & 23.4 & 29 & 11.5 & 88 & 34.9 & $13,12,22,23$ & 8.2 & 0.004 \\
\hline Impaction & 15 & 5.9 & 4 & 1.5 & 19 & 7.5 & 13,23 & 0.029 & 0.86 \\
\hline Peg-shaped lateral incisors & 5 & 1.9 & 3 & 1.19 & 8 & 3.1 & 12,22 & 1.04 & 0.3 \\
\hline Agenesis & 22 & 8.7 & 3 & 1.19 & 25 & 9.9 & $22,12,35,31$ & 1.7 & 0.18 \\
\hline Supernumerary & 0 & 0 & 3 & 1.19 & 3 & 1.19 & Sup. Lower lateral & 10.3 & 0.001 \\
\hline Dilacerations & 0 & 0 & 1 & 0.39 & 1 & 0.39 & 21 & 3.4 & 0.06 \\
\hline
\end{tabular}

Table (3) distribution of dental anomalies in each malocclusion group.

\begin{tabular}{|l|l|l|l|l|}
\hline Anomaly & $\begin{array}{l}\text { Class } \\
\text { I }\end{array}$ & $\begin{array}{l}\text { Class II } \\
\text { div.1 }\end{array}$ & $\begin{array}{l}\text { Class II } \\
\text { div.2 }\end{array}$ & $\begin{array}{l}\text { Class } \\
\text { III }\end{array}$ \\
\hline $\begin{array}{l}\text { Thin, pippet- } \\
\text { shaped roots }\end{array}$ & 46 & 19 & 5 & 6 \\
\hline Ectopic eruption & 59 & 19 & 8 & 2 \\
\hline Agenesis & 13 & 6 & - & 6 \\
\hline Short blunt root & 39 & 12 & 2 & 8 \\
\hline Impaction & 15 & 4 & - & - \\
\hline $\begin{array}{l}\text { Peg-shaped } \\
\text { laterals }\end{array}$ & 5 & 3 & - & - \\
\hline Dilaceration & 1 & - & - & - \\
\hline Supernumerary & 1 & 2 & - & - \\
\hline
\end{tabular}

\section{DISCUSSION:}

Many researches have been conducted to evaluate the prevalence of various dental anomalies ${ }^{13,14,15}$. However no reported study has been conducted on Libyan orthodontic patients. In this study, $53.5 \%$ of the total study group had at least 1 dental anomaly, Significant differences in the occurrence of dental anomalies were observed between this study and previous epidemiological studies ${ }^{16}$ while some studies reported small frequencies of dental anomalies exhibited in their research sample ${ }^{17}$ other investigation found higher incidence of dental anomalies in their study sample as we did ${ }^{13}$. This may be because all of the patients involved in those studies were orthodontic patients with a greater tendency to show dental anomalies such as agenesis, impaction, ectopic eruption, and peg-shaped lateral incisors. Varying definitions of dental anomalies may also account for different results. In our research ectopic eruption was the most prevalent dental anomaly, it accounted for $34.9 \%$ of the patients with at least one dental anomaly, followed by thin pippet-shaped roots and short blunt roots. which accounted for $30.1 \%$ and $24.2 \%$ respectively, These results were different than the outcome of previous investigations wherein the dental agenesis was found to be the most prevalent dental anomaly in orthodontic patients ${ }^{2,6}$ this could be attributed to the differences of the racial and ethnic origin of varies samples and to the recording techniques. According to the literature Class I malocclusion has the highest incidence of dental anomalies compared to the other malocclusion groups, similar results were reported in previous researches which investigated the relation between dental anomalies incidence and the type of dentoskeletal growth ${ }^{2,6}$. however it is 
important to mention that this outcome could be related to the fact that the number of Class I malocclusion in this study sample is large compared to the other malocclusion group which could affect the statistical analysis of the whole study. Regarding the gender differences, some authors found statistically insignificant differences for the incidence of dental anomalies between male and female ${ }^{13,15}$, whereas others reported significant differences by sex for certain dental anomalies ${ }^{18,19}$. Our statistical analysis outcome show that male have more ectopic eruption and short blunt root compared to female while the other type of dental anomalies show insignificant differences. In general, girls report and seek orthodontic treatment more frequently than boys ${ }^{20,21}$. This factor was reflected in the sample of the present study as well, which could affect the statistical outcome of our analysis,

\section{REFERENCES:}

1) Proffit WR. The development of orthodontic problems. In: Proffit WR, editor. Contemporary orthodontics. 2nd ed. St Louis:Mosby; 1997. p. 110

2) Uslu O, Akcam MO, Evirgen $S$, Cebeci L. Prevalence of dental anomalies in various malocclusions. Am J Orthod Dentofacial Orthop 2009; 135:328-35

3) Jarvin S, Lehtinen L. Supernumerary and congenitally missing primary teeth in Finnish children. An epidemiologic study. Acta Odontol Scand 1981;39:83-6.)

4) Al-Emran S. Prevalence of hypodontia and developmental malformation of permanent teeth in Saudi Arabian schoolchildren. Br J Orthod 1990;17:115-8

5) Al-Jasser, N. M. "Cephalometric evaluation for Saudi population using the Downs and Steiner analysis." J Contemp Dent Pract 6.2 (2005): 52-63

6) Qalab A, Abida A, Amjad N, Muhammad A, Frequency of dental anomalies in various malocclusions in orthodontic patients, pakistan oral \& dental journal vol 30, no. 1, june 2010

7) Apajalahti S, Hölttä P, Turtola L, Pirinen S. Prevalence of short-root anomaly in healthy young adults. Acta Odontol Scand 2002;60:56-9

8) Eva Levander and Olle Malmgren Evaluation of the risk of root resorption during orthodontic treatment: A study of upper incisors European Journal of Orthodontics 10 (1988) 30-38 therefore the sample variation between male and female had to be considered.

\section{CONCLUSION:}

A significant numbers of orthodontic patients had at least one dental anomaly (53.5\%) in this study. A remarkably high rate of dental anomalies was recorded in orthodontic patients. In this study ectopic eruption was the most prevalent dental anomaly $(34.9 \%)$ followed by thin pippet-shaped roots and short blunt root $(30.1 \%, 24.2 \%)$ respectively. Male subjects showed more ectopic eruption and short blunt root then female Class I malocclusion had the most prevalent dental anomalies compared to the other malocclusion groups. The difference in prevalence compared with previous studies might arise from racial differences or differences in diagnostic criteria.

9) Toutountzakis N, Kataris N. Ectopic eruption of the maxillary first permanent molar. Orthod Epitheorese 1990;2:117-28

10) Thilander B, Jakobsson SO. Local factors in impaction of maxillary canines. Acta Odontol Scand 1968;26:145-68

11) . Glossary of prosthodontic terms, J Prosthet Dent 81 (1999) 11

12) Hamasha AA, Al-Khateeb T, Darwazeh A. Prevalence of dilacerations in Jordanian adults. Int Endod J 2002;35:910-2

13) Thongudomporn U, Freer TJ. Prevalence of dental anomalies in orthodontic patients. Aust Dent J 1998;43:395-8.)

14) McCulloch KJ, Mills CM, Greenfeld RS, Coil JM. Dens evaginatus from an orthodontic perspective: report of several clinical cases and review of the literature. Am J Orthod Dentofacial Orthop 1997;112:670-5

15) Endo T, Ozoe R, Kubota M, Akiyama M, Shimooka S. A survey of hypodontia in Japanese orthodontic patients. Am J Orthod Dentofacial Orthop 2006;129:29-35

16) Basdra EK, Kiokpasoglou MN, Komposch G. Congenital tooth anomalies and malocclusions: a genetic link? Eur J Orthod 2001;23:145-52

17) Ayse Tuba Altug-Atac Dilek Erdem Prevalence and distribution of dental anomalies in orthodontic patients Am J Orthod Dentofacial Orthop 2007;131:510-4

18) Brook AH. Dental anomalies of number, form and size: their prevalence in British schoolchildren. J Int Assoc Dent Child 1974;5:37-53 
19) Bergstrom K. An orthopantomographic study of hypodontia, supernumeraries and other anomalies in school children between the ages of 8-9 years. An epidemiological study. Swed Dent J 1977;1:145-57

20) Afzal A, Ahmed I, Vohra F. Frequency of malocclusion in a sample taken from Karachi population. Ann Abbasi Shaheed Hosp Karachi Med Dent Coll 2004; 9: 588-89

21) Kerosuo H, Abdulkarim E, Kerosuo E. Subjective need and orthodontic treatment experience in a Middle East country providing free orthodontic services: a questionnaire survey. Angle Orthod 2002; 72: $565-70$ 